\title{
Phreatic Surface Estimation In MSE Wall With Geocomposite Back Drainage
}

Avirut Chinkulkijniwat ( $\square$ avirut@sut.ac.th )

Suranaree University of Technology

\section{Suksun Horpibulsuk}

Suranaree University of Technology

\section{Hai La Duong}

Suranaree University of Technology

\section{Thien Do Quang}

Hue University of Science

\section{Research Article}

Keywords: MSE wall, protected area, maximum water level, geonet transmissivity, linear association

Posted Date: June 21st, 2021

DOI: https://doi.org/10.21203/rs.3.rs-617560/v1

License: (c) (i) This work is licensed under a Creative Commons Attribution 4.0 International License. Read Full License 


\title{
PHREATIC SURFACE ESTIMATION IN MSE WALL WITH GEOCOMPOSITE
}

BACK DRAINAGE

\begin{abstract}
Avirut Chinkulkijniwat, B.Eng. (Hons.), M.Eng., D.Eng.
Professor, Center of Excellence in Civil Engineering, School of Civil Engineering, School of Civil Engineering, Institute of Engineering, Suranaree University of Technology, 111 University Avenue, Suranaree, Muang, Nakhon Ratchasima 30000, THAILAND, E-mail : avirut@sut.ac.th
\end{abstract} (1)

Suksun Horpibulsuk, B.Eng. (Hons.), M.Eng., Ph.D., P.E.

Professor, School of Civil Engineering, Institute of Engineering, Suranaree University of Technology, 111 University Avenue, Suranaree, Muang, Nakhon Ratchasima 30000, THAILAND, E-mail :suksun@g.sut.ac.th

\section{Hai La Duong, B.Eng., M.Eng.}

Ph.D .Scholar, School of Civil Engineering, Institute of Engineering, Suranaree University of Technology, 111 University Avenue, Suranaree, Muang, Nakhon Ratchasima 30000, THAILAND, E-mail :hailaduong9@gmail.com

\section{Thien Do Quang, B.Eng., M.Eng., D.Eng.}

Associate Professor, Hydrogeology and Engineering Geological Department, Faculty of Geography and Geology, Hue University of Sciences, Nguyen Hue St, Hue City, Thua Thien Hue 49000, VIETNAM, E-mail: dqthien@ @ueuni.edu.vn

Date Written 09 June 2021

Word count 2613

NOTE :The corresponding author is the first author .Mail communication may be addressed to the corresponding author Avirut Chinkulkijniwat, School of Civil Engineering, Suranaree University of Technology, 111 University Avenue, Muang District, Nakhon Ratchasima 30000, THAILAND 
ABSTRACT

This study proposes a simple mathematic model for approximating the level of phreatic surface inside the protected zone in mechanical stabilized earth wall with back drain installation though the position of phreatic surface at the drainage interface $\left(h_{o}\right)$ which reflects the maximum level of phreatic surface in the protected zone. The proposed model was established based on dataset taken from 180 simulation cases caried out in Plaxis environment. Regression results present a combination of significant effects and major role to maximum water level in the protected zone $\left(h_{o}\right)$ of a ratio of length from upstream water to the drainage face to the wall height $(L / H)$, a soil permeabilities coefficient $(k)$ and a transmissivity of the drainage material $\left(T_{n e t}\right)$. The proposed model can facilitate design of drainage material to achieve desired level of phreatic surface in the protected zone.

Keywords: MSE wall, protected area, maximum water level, geonet transmissivity, linear association 
Although drainage system was properly installed behind mechanical stabilized earth (MSE) wall, failures happened during long term rainfall have been mentioned in many reports (Yoo and Jung, 2006; Koerner and Koerner, 2018; Zhang et al., 2015; Koerner and Koerner, 2015; Vahedifard et al., 2017). The wide distribution of high water content in the protected zone was a major source for many types of failure (Zhang et al., 2015; Chinkulkijniwat et al., 2016). To narrow the high water content zone, the backfill soil must consist of least fine particle and the level of phreatic surface inside the protected zone must be minimized. Good estimation of phreatic level inside the protected zone is, therefore, vital for design of MSE wall. This study focuses accurate estimation of phreatic level inside the protected zone though the high of phreatic surface at the drainage interface in the protected zone $\left(h_{o}\right)$. The $h_{o}$ is considered as the maximum level of phreatic surface in the protected zone and reflects the effectiveness of the drainage system.

Previous reports, i.e. Koerner and Koerner (2018), Koerner and Koerner (2015). Vahedifard et al. (2017), indicated that there were many factors influencing the $h_{o}$ variation such as soil none of the previous attempts had been devoted to estimate the magnitude of $h_{o}$ comprehensively. To date, engineers design the required transmissivity of drainage layer using a classical Dupuit's formular with an assumption that the phreatic level inside the protected zone is zero. Previous study from the authors (Chinkulkijniwat et al., 2016, Bui Van et al., 2017, La Duong et al., 2021) reports none zero phreatic level inside the protected zone even after assigning transmissivity of drainage layer greater than that provided by Dupuit's equation. For a given wall geometry of homogeneous soil, La Duong et al. (2021) reported linear relationship between $h_{o}$ and logarithm of geonet transmissivity $\left(T_{n e t}\right)$. Furthermore, the gradient 
upstream soil. This paper extends this important finding to propose a closed form equation for $h_{o}$ estimation. Data used in this study were gathered from 180 sets of numerical calculation extracted from well calibrated Plaxis-2D model (Chinkulkijniwat et al., 2016). Steady-state flow conditions were focused in this study to quantify the final state of ground water flow in MSE wall .The proposed equation will assist drainage design in MSE wall with back drain installation.

\section{METHODOLOGY}

\section{Research background}

Soil-water model is based on van Genuchten model (Eq .1a) (van Genuchten, 1981) and van Genuchten -Mualem model (Eq.1b), which is an integration of the van Genuchten model with the Mualem hypothesis (Mualem, 1976), were employed to approximate the water retention curve and permeability functions for every porous media in the MSE wall problem . The models gave the following equations :

$S_{e}=\frac{s-S_{\text {res }}}{S_{\text {sat }}-S_{\text {res }}}=\left[1+\left(\alpha\left|h_{p}\right|\right)^{n}\right]^{-m}$

$k_{r}\left(S_{e}\right)=S_{e}^{0.5}\left[1-\left(1-S_{e}^{1 / m}\right)^{m}\right]^{2}$

In the above equations, $S_{e}$ is effective degree of saturation [-], $S$ is degree of saturation [-], $S_{\text {res }}$ is residual saturation at very high values of suction [-], $S_{\text {sat }}$ is the degree of saturation at saturated state [-], $h_{p}$ is matric suction head [m], and $k_{r}$ is the relative permeability coefficient $[\mathrm{m} / \mathrm{sec}], \alpha\left[\mathrm{m}^{-1}\right]$ and $n[-]$ are fitting parameters which represent respectively the air-entry head of the soil and the rate of water extraction from the soil once the air entry head has been exceeded, while $m[-]$ is assigned the value $1-1 / n[7]$.

\section{Simulation scenarios for linear association analysis}

Well calibrated MSE wall with back drain installation model in Plaxis environment (Figure 1) reported by Chinkulkijniwat et al. (2016) was employed to approximate the maximum phreatic 
level in the protected zone of MSE wall $\left(h_{o}\right)$. The upstream water level in all calculations was set equal to the wall height to imitate vital scenario of the MSE wall in mountainous terrain, where heavy rainfall could raise the upstream water level to equal heigh of the wall. In this study, the upstream-, foundation-, and backfill-soils were assigned identically. Six soil types; including coarse sand (Konukcu et al., 2004), sandy soil (Chinkulkijniwat et al., 2016), clayey soil (Szymkiewicz et al., 2015), lateritic soil (Bui Van et al., 2017) and clay (Koerner and Koerner, 2015), were assigned to perform the calculation. Saturated permeability coefficient and van Genuchten parameters these soils are given in Table 1. As for the wall dimensions ratio; including the distance from the wall base to the impervious boundary to the wall height $(D / H)$, the protected zone width to the wall height $(W / H)$, and the distance from the upstream water source to the drainage face to the wall height $(L / H)$, La Duong et al. (2021) reports that except the dimension ratio $L / H$, other wall dimension ratios play small to negligible role to the magnitude of $h_{o} / H$. Accordingly, for wall dimension set up in this study, the wall height $(H)$, distance from the wall base to the impervious boundary $(D)$, and the protected zone width $(W)$ were fixed at $2.0 \mathrm{~m}, 0.8 \mathrm{~m}$, and $2.0 \mathrm{~m}$, respectively. The shape parameter $L$ was varied in range from $L / H$ of 1.0 to $L / H$ of 2.5 as stated in Table 2 . Geonet transmissivity was controlled by geonet thickness $\left(t_{n e t}\right)$ and geonet permeability $\left(k_{n e t}\right)$ through the relationship written in Eq. 2, $T_{n e t}=k_{\text {net }} \times t_{\text {net }}$

where $T_{n e t}$ is geonet transmissivity $\left(\mathrm{m}^{2} / \mathrm{sec}\right), t_{n e t}$ is geonet thickness $(\mathrm{m})$ and $k_{n e t}$ is geonet permeability $(\mathrm{m} / \mathrm{sec})$. The assigned hydrological properties of geonet as thickness $\left(t_{n e t}\right)$, permeability $\left(k_{n e t}\right)$ are also given in Table 2 . Totally, 180 calculation cases were conducted in this study. Within this dataset, 18 calculation results yielding $h_{o}$ value of $0.001 \mathrm{~m}$ were eliminated from the analysis. Since the smallest $h_{o}$ readable from the calculations was 0.001 $\mathrm{m}$, including this dataset might deviate the analyzed result. 


\section{RESULTS AND DISCUSSION}

135

136

137

138

The relationships between $h_{o}$ and $\log \left(T_{n e t}\right)$ for coarse sand, sandy soil, clayey sand, lateritic soil, and clay extracted from Plaxis calculation are respectively shown in Fig. 2a, 2b, 2c, 2d, and 2e. The drop of $h_{o}$ with the increase of $\log \left(T_{n e t}\right)$ reflects the greater amount of water allow to flow along the drainage channel. Linear regression was employed to fit the $h_{o}-\log \left(T_{n e t}\right)$ relationship. All plots reflect themselves best fit with linear association via the coefficient of determination $r^{2}$ greater than 0.96 . Although the variation of $h_{o}$ with $\log \left(T_{n e t}\right)$ was well fitted through linear regression, no further correlation was found along these plots. Since the permeability coefficient of the upstream soil $(k)$ plays important role to the drop of $h_{o}$ with increasing $T_{\text {net }}$ (La Duong et al, 2021), the permeability coefficient $(k)$ was included in the $T_{\text {net }}$ term as $\log \left(T_{\text {net }} / k\right)$ and plotted with $\log \left(h_{o}\right)$ as shown in Figure 3. The plots exhibit similar pattern for all values of shape parameter $L$, hence the shape parameter $L$ must be included to normalize the data. After trial and error, the term $\log \left(T_{\text {net }} / k\right)$ was transformed to $\log \left(T_{\text {net }} / k^{(10+L / H) / 10}\right)$ and the variation of $\log \left(h_{o}\right)$ with $\log \left(T_{n e t} / k^{(10+L / H) / 10}\right)$ exhibit unique relationship with the coefficient of determination $r^{2}$ of 0.93 as shown in Figure 4. The equation for $h_{o}$ estimation in MSE wall with geocomposite back drainage is, hence, delivered as:

$\log \left(h_{o}\right)=-0.16-0.56 \log \left(T_{n e t} / k^{(10+L / H) / 10}\right)$

To verify the above equation, 12 extra Plaxis calculations having the influence variables were randomly assigned to the model. Table $\mathbf{3}$ presents variation of influence variables and the corresponding $h_{o}$ values extracted from these extra calculations. The $h_{o}$ values yield from Eq. 3 are also presented in this table. Comparison between ho values calculated from Plaxis and that from Eq. 3 is shown in Figure 5. The coefficient of determination $r^{2}$ along 1:1 line is 0.96 indicating level of accuracy of the $h_{o}$ prediction using Eq. 3.

\section{CONCLUSION}

Following points are drawn from this study: 
- Simple mathematic model for approximating the maximum water level in the protected zone $\left(h_{o}\right)$ for mechanical stabilized earth wall with back drain installation was established through dataset calculated from a well calibrated model in Plaxis environment.

- Based on previous report (La Duong et al., 2021), important parameters playing role to the change of $h_{o}$ are 1) permeability coefficient of upstream soil $\left.(k), 2\right)$ transmissivity of the back drain $\left(T_{n e t}\right)$, and 3) a ratio of the distance from the upstream water source to the drainage face to the wall height $(L / H)$. Hence, the model was established based on variation of these 3 parameters.

- The proposed equation was established based on identical soil at the upstream- and protection-zones. In practical situation, the soil located in protected zone always possesses its permeability coefficient no less than that of the upstream soil. According to Bui Van et al. (2017) and La Duong et al. (2021), if the soil in the protected zone possesses more permeable than the soil in the upstream side does, the flow path reflection results in the lower phreatic surface in the protected for the more permeable soil in the protected zone than that for the less permeable soil in the protected zone. As such, magnitude of $h_{o}$ approximated from the proposed equation is conceptually no lower than that take place in MSE wall having higher soil permeability in the protected zone than that in the upstream side, i.e. the propose equation yields conservative results.

\section{ACKNOWLEDGEMENT}

This work was supported by Suranaree University of Technology (Grant number (IRD7-71263-12-06).

\section{STATEMENT FOR CONFLICT OF INTEREST}

On behalf of all authors, the corresponding author states that there is no conflict of interest 


\section{REFERENCES}

184

185

186

187

Acharya, S., Jawitz, J. W., and Mylavarapu, R. S., 2012. Analytical expressions for drainable and fillable porosity of phreatic aquifers under vertical fluxes from evapotranspiration and recharge, Water Resour. Res., 48.

Bui Van, D., Chinkulkijniwat, A., Horpibulsuk, S., Yubonchit, S., Limrat, I., Arulrajah, A. and Jothityangkoon, C., 2017. Steady flow in mechanically stabilised earth walls using marginal soils with geocomposite. Geosynthetics International. 24(6), 590-606.

Chinkulkijniwat, A., Horpibulsuk, S., Bui Van, D., Udomchai, A., Goodary, R., Arulrajah, A., 2016. Influential factors affecting drainage design considerations for mechanical stabilised earth walls using geocomposite. Geosynthetics International. 24(3), 224-241.

La Duong, H., Chinkulkijniwat, A., Horpibulsuk., Do Quang T., Yaowarat, T., 2021. Steady state groundwater in mechanical stabilized earth walls of various dimensions with geocomposite back drain installation. International Journal of geomechanics (in printed).

Koerner, R. M., \& Koerner, G. R., 2015. Lessons learned from geotextile filter failures under challenging field conditions. Geotextiles and Geomembranes. 43(3), 272-281.

Koerner, R. M., \& Koerner, G. R. 2018. An extended data base and recommendations regarding 320 failed geosynthetic reinforced mechanically stabilized earth (MSE) walls. Geotextiles and Geomembranes, 46(6), 904-912.

Konukcu, F., Istanbulluoglu, A., and Kocaman, I., 2004. Determination of water content in drying soils: Incorporating transition from liquid phase to vapour phase. Australian Journal of Soil Research. 42(1), 1-8.

Mualem Y. 1976. A new model for predicting the hydraulic conductivity of unsaturated porous stone media. Water Resource Research. 12(3), 513-522.

Plaxis-2D, 2018. Scientific and Reference manual. Plaxis bv, Delft, Netherlands. 
Szymkiewicz, A., Tisler, W., Burzyński, K., 2015. Examples of numerical simulations of twodimensional unsaturated flow with VS2DI code using different interblock conductivity averaging schemes. Geologos. 21(3), 161-167.

Vahedifard, F., Tehrani, F.S., Galavi, V., Ragno, E., AghaKouchak, A., 2017. Resilience of MSE Walls with Marginal Backfill under a Changing Climate: Quantitative Assessment for Extreme Precipitation Events. Geotechnical and Geoenvironmental Engineering. 143(9), 04017056.

van-Genuchten, 1980. A closed-form Equation for Predicting the Hydraulic Conductivity of Unsaturated Soils. Soil science society of America journal. 44(5), 892-898.

Yoo, C., Jung, H.Y., (2006). Case history of Geosynthetic Reinforced Segmental Retaining Wall Failure. Journal of Geotechnical and Geoenvironmental Engineering 132, No. 12, $1538-1548$.

Zhang, C., Chen, X, Fan, W., 2015. Overturning Stability of a Rigid Retaining Wall for Foundation Pits in Unsaturated Soils. International Journal of Geomechanics. 16(4), 06015013.

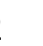

(1)

(4)

\section{5}

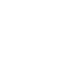

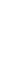

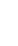


Table 1. Permeability coefficient and van Genuchten parameters of the studied materials.

\begin{tabular}{lccccc}
\hline Material & $\begin{array}{c}\text { Permeability } \\
(\mathrm{m} / \mathrm{sec})\end{array}$ & $\begin{array}{c}\alpha \\
\left(\mathrm{m}^{-1}\right)\end{array}$ & $\begin{array}{c}\mathrm{n} \\
(-)\end{array}$ & $\begin{array}{c}\mathrm{S}_{\text {sat }} \\
(-)\end{array}$ & $\begin{array}{c}\mathrm{S}_{\text {res }} \\
(-)\end{array}$ \\
\hline Coarse sand & $1.3 \times 10^{-3}$ & 49.36 & 1.53 & 1.0 & 0.002 \\
Sandy soil & $1.97 \times 10^{-4}$ & 20 & 1.5 & 1.0 & 0.03 \\
Clayey sand & $4.1 \times 10^{-5}$ & 12.4 & 2.28 & 1.0 & 0.14 \\
Lateritic soil & $4.0 \times 10^{-6}$ & 0.8 & 1.4 & 1.0 & 0.03 \\
Clay & $5.56 \times 10^{-7}$ & 0.08 & $8.0 \times 10^{-5}$ & 0.74 & 0.12 \\
Geotextile & $0.023(0.0037)^{\mathrm{a}}$ & 20 & 2.5 & 0.8 & 0.03 \\
Geonet & 0.8 & 600 & 40 & 1.0 & 0.0 \\
\hline
\end{tabular}

${ }^{a}$ Permeability of geotextile in lateral direction.

Table 2. Variable setup of 180 simulations in Plaxis environment 


\begin{tabular}{lcc}
\hline Scenario & Prescribed soil & Reference \\
\hline$A$ & Coarse sand & Konukcu et al. (2004) \\
$B$ & Sandy soil & Chinkulkijniwat et al. (2016) \\
$C$ & Clayey sand & Szymkiewicz et al. (2015) \\
$D$ & Lateritic soil & Bui Van et al. (2017) \\
$E$ & Clay & Koerner and Koerner (2015) \\
\hline Fixed parameter & & 1.6 \\
\hline$W(m)$ & Protected zone width & 2.0 \\
$H(m)$ & MSE wall height & 0.8 \\
$D(m)$ & Distance from the wall base to the impervious boundary & Varied value \\
\hline Varied parameter & Definition & $2.0,3.0,4.0,5.0$ \\
\hline$L(m)$ & Length from upstream water to the drainage face & $10,15,20$ \\
$t_{n e t}(\mathrm{~mm})$ & Geonet thickness & $0.8,0.08,0.008$ \\
$k_{n e t}(\mathrm{~m} / \mathrm{sec})$ & Geonet permeability & \\
\hline Upstream water level $\left(H_{w}\right)$ is kept as constant 2.0 for all simulation cases
\end{tabular}

Table 3. Assigned variables in 12 verified cases and the corresponding $h_{o}$ values from Plaxis calculation and that from the proposed equation.

\begin{tabular}{|l|l|l|l|l|l|l|}
\hline $\begin{array}{l}\text { Soil type and its } \\
\text { permeability }\end{array}$ & $\begin{array}{l}\text { Case } \\
\text { no. }\end{array}$ & $\begin{array}{l}H \\
(\mathrm{~m})\end{array}$ & $\begin{array}{l}L \\
(\mathrm{~m})\end{array}$ & $\begin{array}{l}T_{\text {net }} \\
\left(\mathrm{m}^{2} / \mathrm{sec}\right)\end{array}$ & $\begin{array}{l}h_{o}(\mathrm{~m}) \\
(\text { Plaxis })\end{array}$ & $\begin{array}{l}h_{o}(\mathrm{~m}) \\
\text { (Proposed model) }\end{array}$ \\
\hline \multirow{4}{*}{$\begin{array}{l}\text { Soil type } 1 \\
\mathrm{k}=1.97 \times 10^{-4} \mathrm{~m} / \mathrm{s}\end{array}$} & 1 & 3.5 & 6.5 & $3.0 \times 10^{-3}$ & 0.0875 & 0.1070 \\
\cline { 2 - 7 } & 2 & 4.5 & 3.5 & $6.0 \times 10^{-3}$ & 0.0585 & 0.0704 \\
\cline { 2 - 7 } & 3 & 4.2 & 0.5 & $8.0 \times 10^{-3}$ & 0.126 & 0.0821 \\
\hline \multirow{3}{*}{$\begin{array}{l}\text { Soil type } 2 \\
\mathrm{k}=2.23 \times 10^{-3} \mathrm{~m} / \mathrm{s}\end{array}$} & 1 & 3.2 & 3.0 & $1.7 \times 10^{-3}$ & 0.192 & 0.1322 \\
\cline { 2 - 7 } & 2 & 2.2 & 5.5 & $6.0 \times 10^{-3}$ & 0.1751 & 0.1691 \\
\cline { 2 - 7 } & 3 & 3.8 & 7.7 & $8.0 \times 10^{-3}$ & 0.1311 & 0.1692 \\
\hline \multirow{3}{*}{$\begin{array}{l}\text { Soil type } 3 \\
\mathrm{k}=3.0 \times 10^{-6} \mathrm{~m} / \mathrm{s}\end{array}$} & 4 & 4.3 & 5.0 & $2.7 \times 10^{-2}$ & 0.1514 & 0.1150 \\
\cline { 2 - 7 } & 2 & 4.7 & 2.6 & $3.0 \times 10^{-3}$ & 0.0141 & 0.0097 \\
\cline { 2 - 7 } & 3 & 3.1 & 2.8 & $8.0 \times 10^{-3}$ & 0.0031 & 0.0043 \\
\cline { 2 - 7 } & 4 & 2.6 & 4.2 & $1.2 \times 10^{-3}$ & 0.0104 & 0.0076 \\
\hline
\end{tabular}




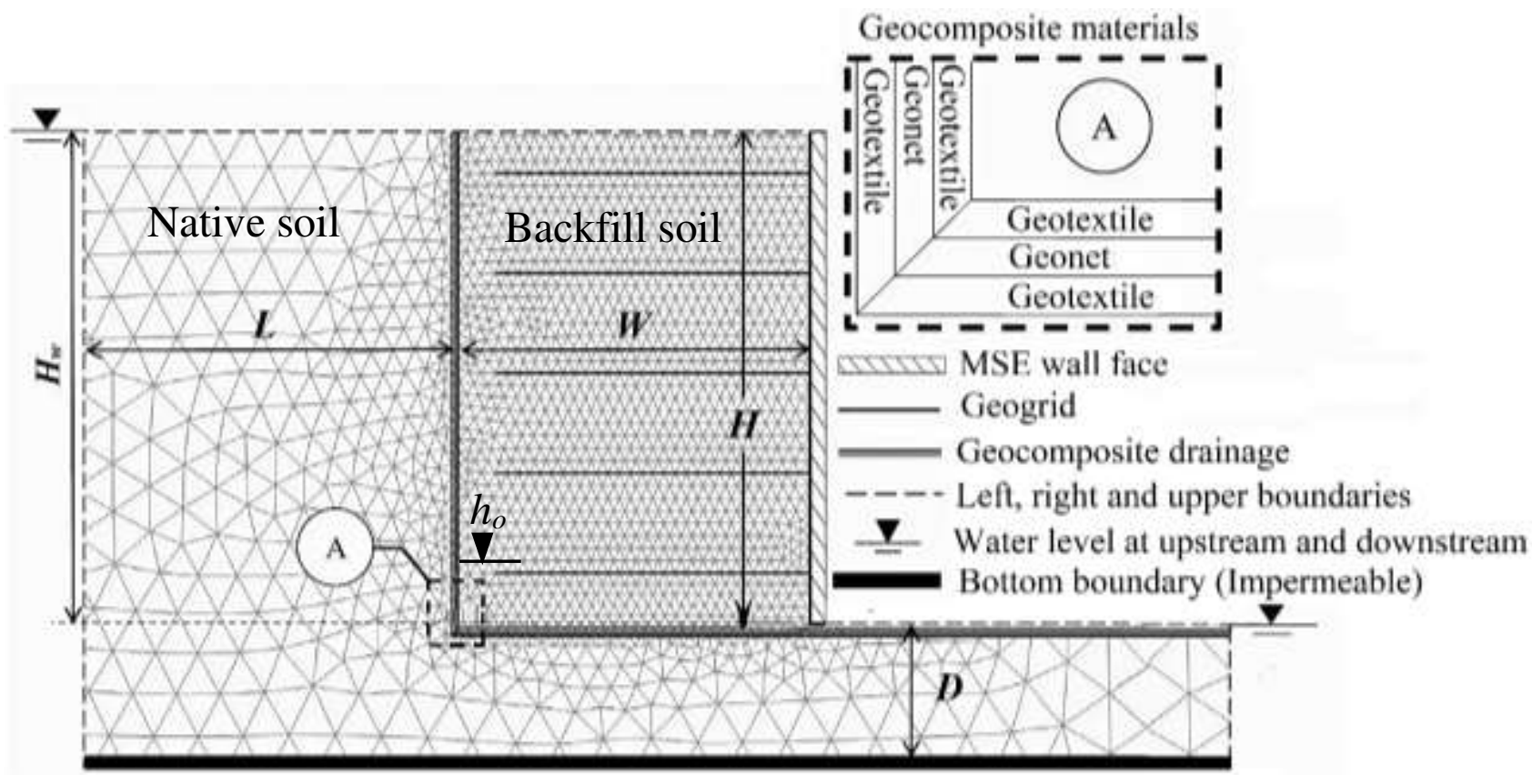

Fig 1. Plaxis model of mesh discretization with $h_{o}$ and the relevant shape parameters of MSE wall with back drain using geocomposite (adopted from Chinkulkijniwat et al. 2016). 

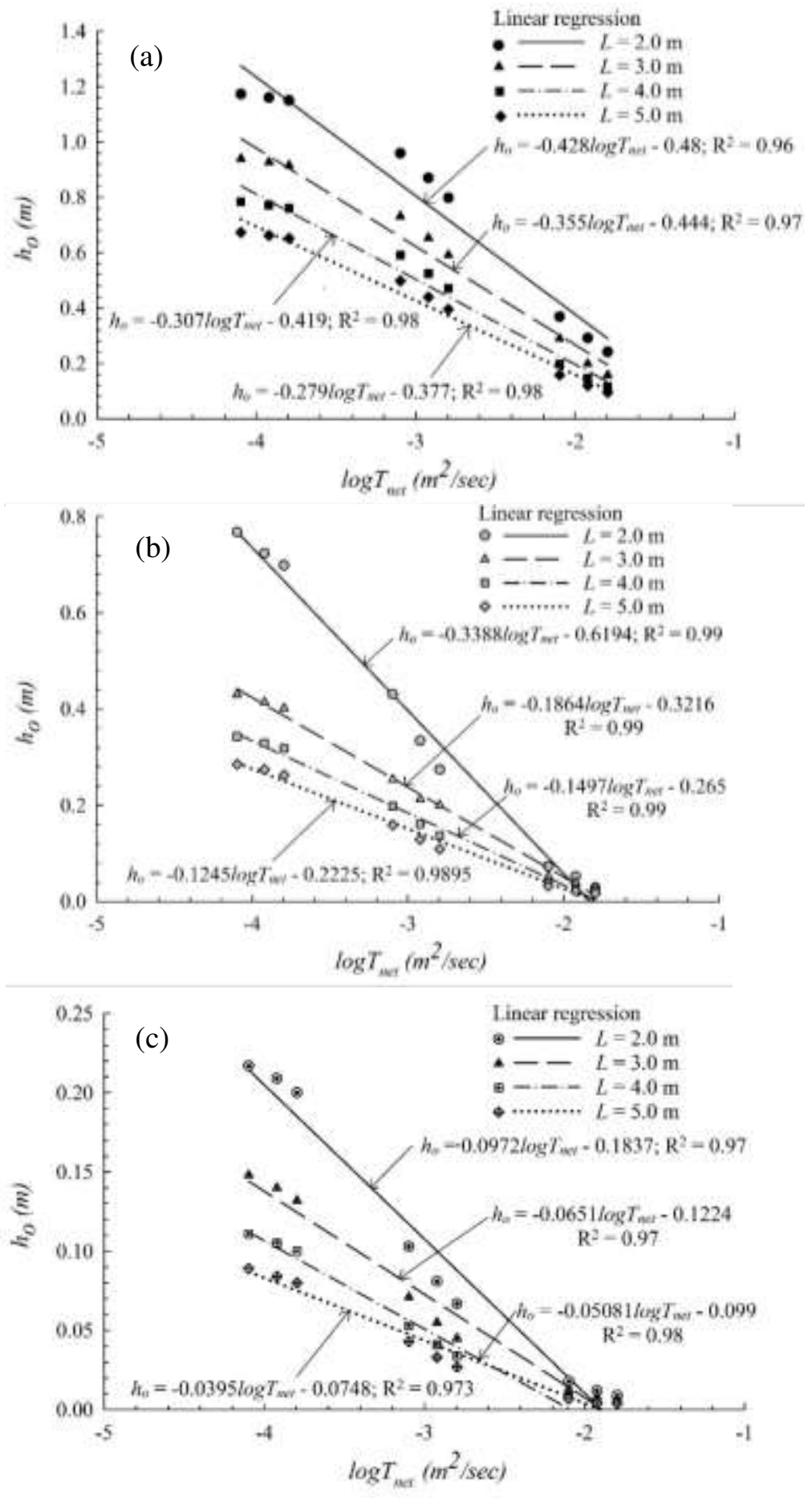

Fig. 2. Linear relationship of $h_{o}$ subject to $\log T_{n e t}$ and various shape parameter $L$ values for (a) coarse sand, (b) sandy soil and (c) clayey sand (e) lateritic soil, and (f) clay. 

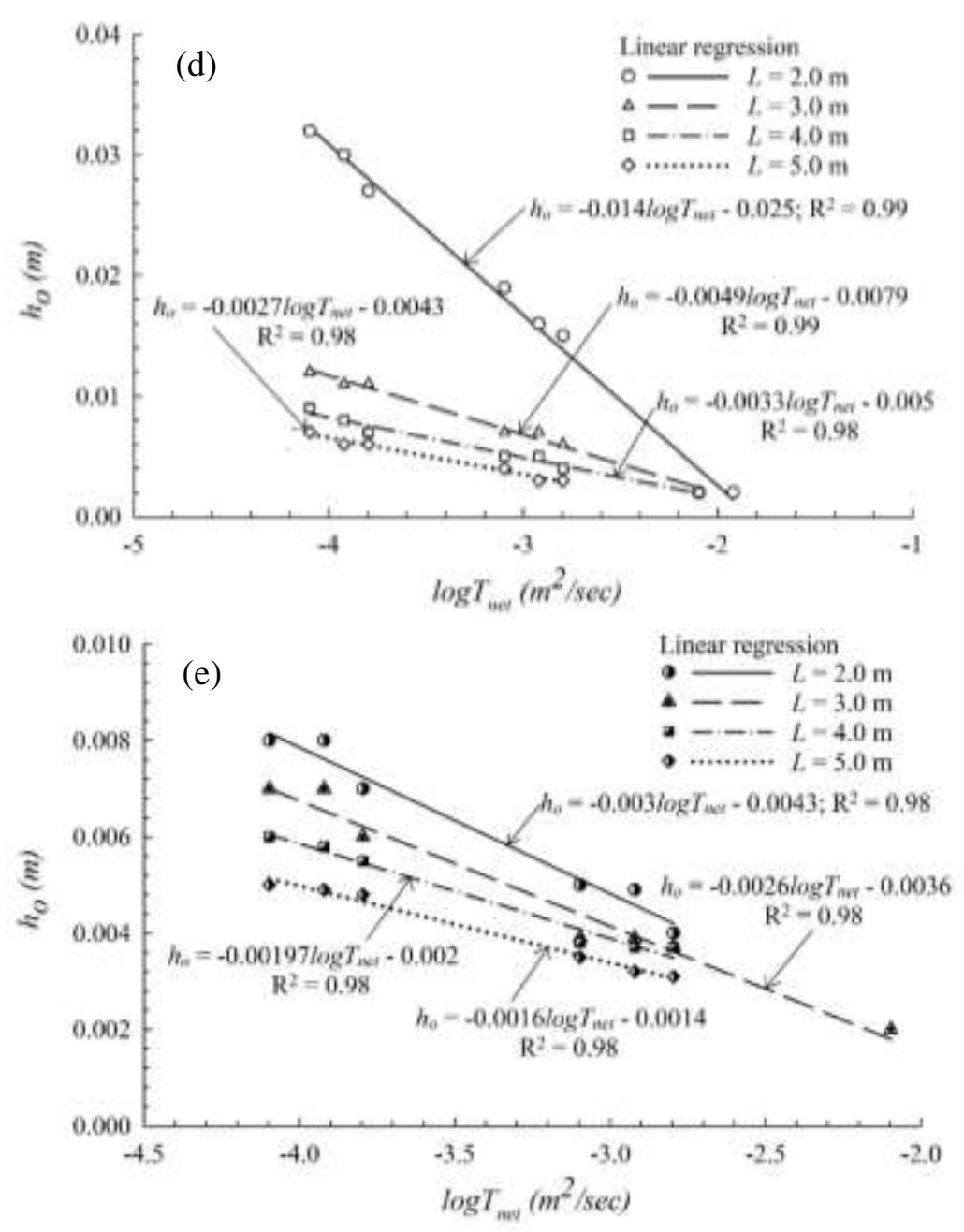

Fig. 2 (cont.). Linear relationship of $h_{o}$ subject to $\log T_{n e t}$ and various shape parameter $L$ values for (a) coarse sand, (b) sandy soil and (c) clayey sand (e) lateritic soil, and (f) clay.

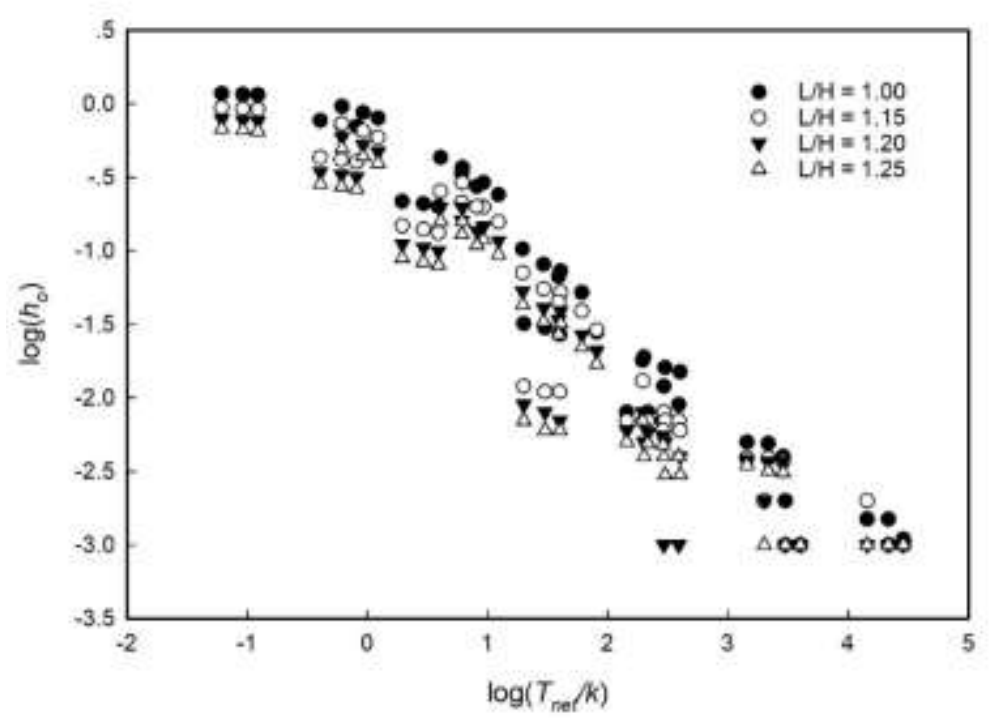

Fig 3. Variation of $\log h_{o}$ and $\log \left(T_{n e t} / k\right)$ for various $L / H$ ratios 


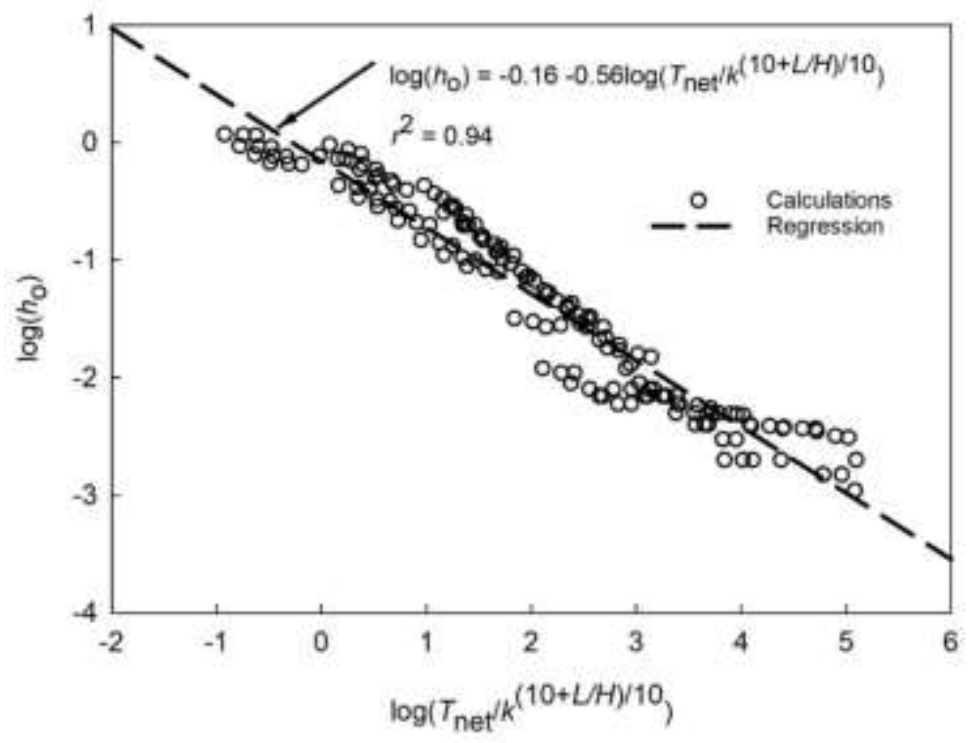

Fig 4. Relationship between $\log h_{o}$ and $\log \left(T_{n e t} / k^{(10+L / H) / 10}\right)$ and regression result

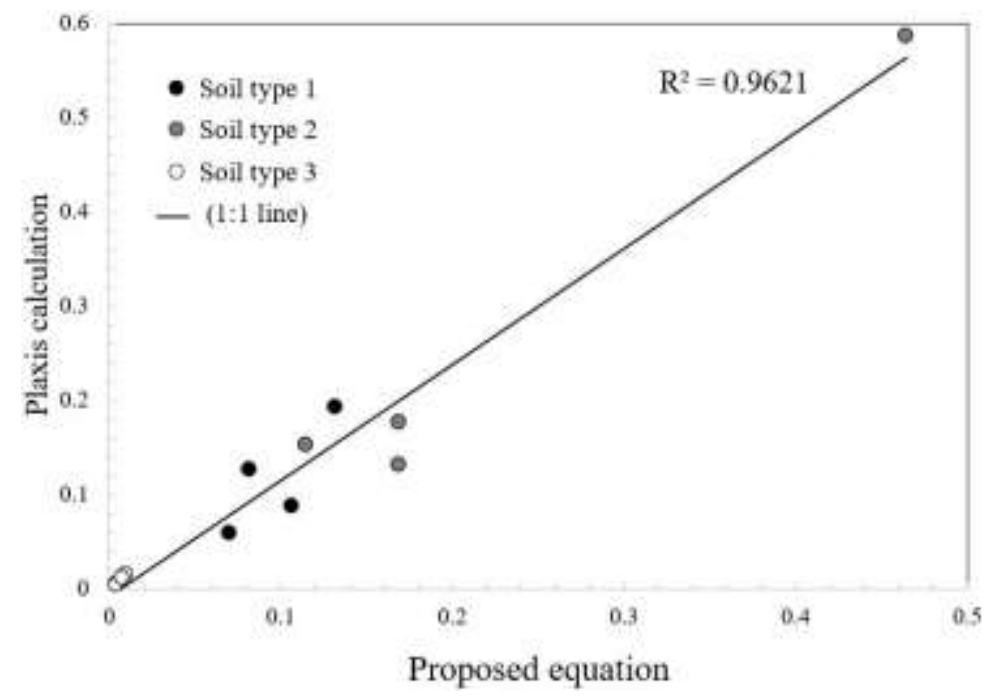

Figure 5. Comparison between $h_{o}$ calculated from Plaxis and that from proposed equation. 